$\xi=-1$

\title{
Biodegradation of Quinoline by Hydrogel Beads of Activated Sludge in the Air-Lift Bioreactor
}

\author{
Haneen Ahmed Khudhair* \\ Environmental Eng. Dept., College of Engineering, Tikrit University, Tikrit, Iraq \\ *Corresponding author E-mail: haneen82@tu.edu.iq
}

\begin{abstract}
Quinoline is a nitrogen heterocyclic compound (NHC) with a molecular formula of $\mathrm{C}_{9} \mathrm{H}_{7} \mathrm{~N}$. Microbial degradation of quinoline occurs under both aerobic and anaerobic conditions. In this study, the aerobic biodegradation of quinoline was investigated with activated sludge which was taken from a municipal sewage wastewater treatment plant in the air-lift bioreactor (ALBR). The activated sludge was entrapped in poly-vinyl-alcohol-calcium alginate (PVA-Ca alginate) hydrogel beads. The optimal conditions for microbial cells entrapment, such as Ca-alginate concentration, biomass concentration in the hydrogel bead and bead size, were determined with concerning to improve the quinoline degradation rate. Also, the initial quinoline concentration was determined. The optimum temperature and initial $\mathrm{pH}$ for quinoline degradation were $30^{\circ} \mathrm{C}$ and $\mathrm{pH} 7-8$, respectively. During the biodegradation process, the culture broth became yellow and brown in turn, which indicated that several intermediates were generated. The results showed that the diversity of microbial cells improves and accelerates the quinoline biodegradation. The repeated use of the hydrogel beads for quinoline degradation was performed and the results revealed that the beads were active and intact up to 4 successive cycles without breakage or loss their stability in the continuous mode. Thus, (PVA-Ca alginate) hydrogel beads have great potential to be a matrix for the cell immobilization in quinoline biodegradation. The various initial concentrations of quinoline $(50,100,250$, and $500 \mathrm{mg} / \mathrm{L})$ were completely degraded in batch-mode experiments; under optimal conditions: PVA conc., $80 \% \mathrm{w} / \mathrm{v}$; calcium alginate conc., $20 \% \mathrm{w} / \mathrm{v}$; initial biomass concentration the hydrogel bead, $3 \mathrm{~mL} / 10 \mathrm{~mL}$ of gel solution; and the hydrogel bead size, about $3 \mathrm{~mm}$ in diameter, at different time intervals $(4,6,10$, and $14 \mathrm{~h})$, respectively.
\end{abstract}

Keywords: activated sludge, air-lift bioreactor, biodegradation, calcium alginate, hydrogel beads, poly vinyl-alcohol, and quinoline.

\section{Introduction}

Quinoline, a representative N-containing heterocyclic compound, is a colorless liquid with a pungent odor and weakly soluble in water (Felczak et al., 2014, Kim et al., 2015).Quinoline is very toxic, volatile and widely occurs in coal tar wastes, fossil-fuel processing activities oil shale, and petroleum (Bai et al., 2010). Moreover, it serves as intermediate and solvent in many chemical industries (Fetzner, 1998, Bai et al., 2010). Quinoline and its derivatives have confirmed mutagenic and carcinogenic activities in mice and rats (Eisentraeger et al., 2008). Due to the high toxicity and nauseating odor of quinoline, additionally to widespread use of antimicrobial agents contained quinoline, the discharge of wastewater contained quinoline does great damage to the environmental quality and human health and also increases the risk of an antibiotic-resistant pathogenic bacterial formation (Lopes and Furlong, 2001, Bai et al., 2010). At low concentration of toxic contaminants including quinoline, the traditional physical and chemical methods of removing these contaminants can be ineffective or uneconomical. The biological techniques based on the microorganisms' ability to degrade a wide range of toxic compounds, the lower energy requirements and special capabilities in treatment and disposal of a variety of pollutants are considered as attractive an alternative to physical and chemical methods (Felczak et al., 2014, Ahmad et al., 2017). There were several studies had been illustrated microbial degradation of quinoline occurs under both aerobic and anaerobic conditions using isolated different bacterial strain coexist in the sewage and soil (Aislabie et al., 1990). Most of these studies were conducted with only a single bacterial strain (Wang et al., 2014). Various bacterial species, especially the genus Pseudomonas, possess the ability to degrade and tolerate quinoline (Lin and Jianlong 2010). Degradation of quinoline can also be achieved by degrading mixed culture of bacteria. The diversity of bacterial community found in activated sludge can eliminate quinoline with higher efficiency than in samples inoculated with a single one. However, most biological methods based on aerobic autotrophic, anaerobic autotrophic and aerobic/anaerobic heterotrophic bacterial communities have been reported as a treatment strategy (Ali \& Okabe, 2015). One of the widest techniques which received widespread attention used for microbial cells immobilization is the entrapment of these cells inside polymeric matrices; which may be natural or synthetic materials (An \& Lo, 2001). Due to the dense entrapment of the activated sludge in the hydrogel beads, a high sludge concentration could be maintained in an entrapment system, without the risk of sludge washout; and provides the potential of reducing the reactor size. Ahmad et al. (2107) employed the immobilized bacterial communities composed of a heterotrophic strain Pseudomonas sp. in the biocarrier of iron oxide nanoparticles (IONPs) to degrade $350 \mathrm{mg} / \mathrm{L}$ of quinoline completely. The air-lift bioreactor (ALBR) classified as pneumatic reactors without any mechanical stirring arrangements for mixing. The turbulence caused by the fluid (air and liquid) flow ensures adequate mixing inside the entire reactor. The upward motion is caused by the introduction of the fluid (air and liquid) which results in recirculating flow in the entire reactor. The 
velocities of fluid will be low and hence the energy consumption is also low. The air-lift bioreactor (ALBR) provides the elimination of attrition effects generally encountered in mechanically agitated reactors, and thus to avoid excess heat produced during mechanical agitation. Additionally, it is ideally appropriate for aerobic cultures since the oxygen mass transfer coefficient are quite high in comparison to stirred reactors. In the present study, firstly, the parameters which affect the activity of hydrogel beads were optimized so that these beads contained microbial cells could be effectively used. Following this, biodegradation of quinoline was studied using air-lift bioreactor (ALBR). The aim of this study was to assess and optimize the entrapment conditions of activated sludge with a view to improving the quinoline degradation rate.

\section{Materials and Methods}

Microorganisms: Activated sludge represents a mixed microbial population was gathered from local municipal sewage treatment plant in Baghdad City, Iraq. The concentered pellets were obtained by centrifuging the activated sludge at $1500 \mathrm{rpm}$ for $10 \mathrm{~min}$.

Chemicals: Quinoline and other chemicals of BDH Chemicals, Poole, England; All other chemicals were of analytical grade.

Nutrient medium: Nutrient medium, described by Wang et al. (2004) was used in the biodegradation experiments. Each liter of nutrient medium contained (in grams) $\mathrm{Na}_{2} \mathrm{HPO}_{4}, 4.26 ; \mathrm{KH}_{2} \mathrm{PO}_{4}$, 2.65; $\mathrm{MgSO}_{4} .7 \mathrm{H}_{2} 0,0.2 ; \mathrm{MnSO}_{4} . \mathrm{H}_{2} 0,0.02 ; \mathrm{FeSO}_{4} .7 \mathrm{H}_{2} 0,0.05$; and $\mathrm{CaCl}_{2}, 0.02$. The salts were dissolved separately (the $\mathrm{pH}$ of the medium was adjusted to 7 , and the solutions were filter sterilized and added to the medium just before use.

Temperature and $\mathbf{p H}$ : The temperature and $\mathrm{pH}$ are important factors in the biodegradation process and should be maintained to achieve a high rate of this process. Since the most of the quinoline degrading bacteria were isolated from wastewater or activated sludge, the optimal growth temperature for these strains ranges between $28^{\circ} \mathrm{C}$ and $30^{\circ} \mathrm{C}$ (Sun et al., 2009). The pH is usually provided at a level between 7 and 8 .

Preparation of hydrogel beads: One of the most attractive properties of the hydrogel is its ability to be swelled by liquids makes it a useful material in biotechnology for entrapment of microorganisms, or cells, etc. (Doriaserrano et al., 2001). The typical procedure for making hydrogel beads is as follows. Firstly, a mixture of poly-vinyl-alcohol (PVA) $(80 \% \mathrm{w} / \mathrm{v})$, calcium alginate $(20 \%$ $\mathrm{w} / \mathrm{v})$, and water was carefully heated to $50^{\circ} \mathrm{C}$ with continuous stirring until complete dissolution. Then the solution was then cooled down to $35^{\circ} \mathrm{C}$. The concentrated sludge was thoroughly mixed with a mixture of PVA-Ca alginate. The size of hydrogel beads was controlled by using the hypodermic syringe. The hydrogel beads of PVA-Ca alginate with of activated sludge, the biomass concentration was $3 \mathrm{ml} / 10 \mathrm{ml}$ of hydrogel mixture, entrapped on them and recovered by incubation after the freezingthawing cycle show that bacteria grow mainly inside the hydrogel. To improve the activity of entrapped cells, the PVA-Ca alginate beads were allowed to be cross-linked with boric acid for a short time (30min) then followed by the freeze-thaw process.

System of ALBR: The experimental setup of the air-lift bioreactor (ALBR) treatment system was designed as shown in Fig.1. ALBR is a jacketed Perspex vessel with a diameter $(\mathrm{D}=50 \mathrm{~mm})$, and inlet bottom diameter $(\mathrm{Di}=8 \mathrm{~mm})$; which is within the allowable design criteria ( $\mathrm{Di} / \mathrm{D}<0.30$ ). The ALBR is connected with water-bath cylinder vessel contained a heater and regulator to control the temperature of the experimental active reactor. ALBR is occupied with required air by an air pump which controlled by flowmeter located at the bottom of the reactor. The experimental system can run continuously under pre-set conditions. The recirculation reactor that contained synthetic wastewater of quinoline is used in this study to determine a regime of operation with respect to reaction rate.

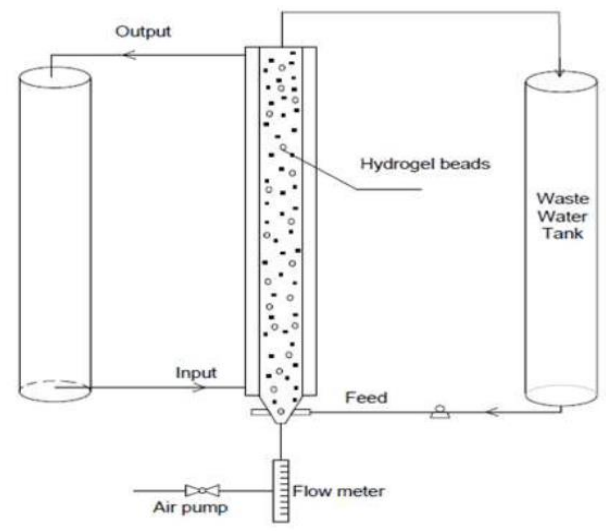

Fig.1: Air-lift bioreactor (ALBR) system

Analytical methods: Prior to the continuous mode experiments of ALBR systems, a set of mode-regime experiments was achieved to optimize the biodegradation of quinoline with respect to calcium alginate concentration, initial biomass concentration, hydrogel bead size, and quinoline concentration as a sole of energy.

\section{Results and Discussion}

Effect of calcium alginate concentration: The biodegradation of $100 \mathrm{mg} / \mathrm{L}$ of quinoline was achieved by the hydrogel beads with different concentrations of calcium alginate, to optimize the final concentration of calcium alginate in the hydrogel bead. The concentrations of calcium alginate in the beads were: 10, 20, and $30 \%$ $\mathrm{w} / \mathrm{v}$ as shown in Fig.2.

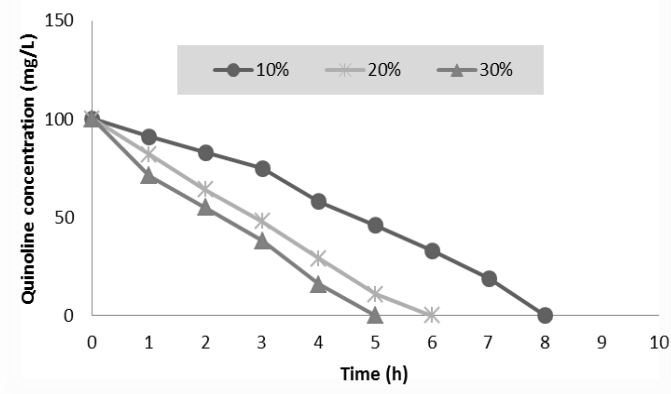

Fig.2: Effect of $\mathrm{Ca}$ alginate concentration on quinoline degradation time (Quinoline conc. $=100 \mathrm{mg} / \mathrm{L}$ by $4 \mathrm{~mm}$ bead size and $3 \mathrm{~mL}$ biomass conc.)

The results indicated that the use of calcium alginate at the lower concentration $(10 \% \mathrm{w} / \mathrm{v})$ gave lower strength and less stability of hydrogel bead and then release the bacterial cells from these beads (Wang et al., 2001). While the higher concentration (over than $30 \% \mathrm{w} / \mathrm{v}$ ) may result in higher mass transfer resistance to the substrate and it is also clear that as the extent of crosslinking increases, the maximum water uptake decreases (Bajpai \& Sharma,

2004). Hence, the concentration of calcium alginate used in this study is $20 \% \mathrm{w} / \mathrm{v}$ (Zhang et al., 2007).

Effect of biomass concentration: The degradation of quinoline was expectedly affected by the initial concentration of activated sludge entrapped in the hydrogel beads. To illustrate the effect of cell concentration, the hydrogel beads applied to the degradation process contained different biomass concentrations; 2 , 3, and $4 \mathrm{~mL}$ of biomass solution $/ 10 \mathrm{~mL}$ of hydrogel mixture. The results of experiments showed that the optimal biomass concertation in the hydrogel beads was $3 \mathrm{~mL} / 10 \mathrm{~mL}$ of hydrogel mixture to degrade 
100mg/L quinoline (Fig.3). This can be attributed to the increase of the initial cell number enhanced quinoline degradation rate (Lin \& Jianlong, 2010; Kim et al., 2015).

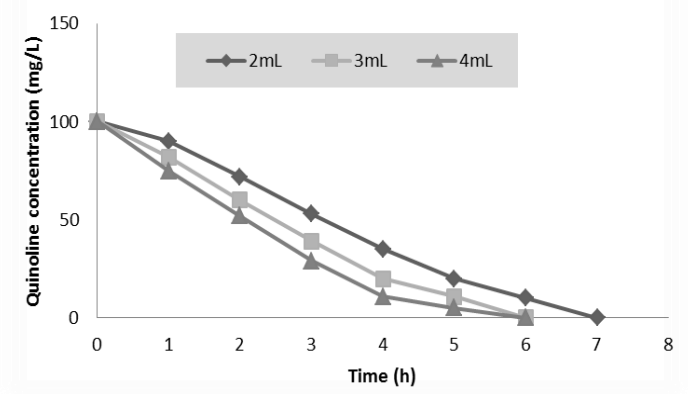

Fig.3: Effect of initial biomass concentration entrapped in the hydroge bead on quinoline degradation (Quinoline conc. $=100 \mathrm{mg} / \mathrm{L}$ by $4 \mathrm{~mm}$ bead size).

As shown in Fig.3, the results indicated that an increase in initial biomass concentration beyond $3 \mathrm{~mL}$ entrapped in $10 \mathrm{~mL}$ of hydrogel mixture did not give a proportional increase in the rate of quinoline degradation. This could be attributed to the unaccounted limitation of mass transfer and the oxygen consumption is faster than of its diffusion into the hydrogel beads (Gosmann \& Rehm, 1986).

Effect of hydrogel bead size: To optimize the hydrogel bead size in the degradation of $100 \mathrm{mg} / \mathrm{L}$ quinoline process, beads with three different diameters of 2,3 , and $5 \mathrm{~mm}$ were used in the batch-mode experiments. The results demonstrated that the optimal diameter of the hydrogel bead is $3 \mathrm{~mm}$; the results were similar to the conclusions of (Jainlong et al., 2001). There was no considerable change when using the bead of $5 \mathrm{~mm}$ in diameter (Fig.4). This might be attributed to the larger size of beads could be obstructed by the degradation process.

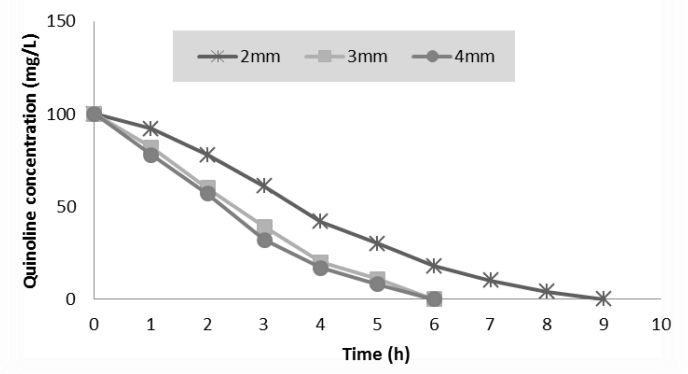

Fig.4: Effect of hydrogel bead size on quinoline degradation (Quinoline conc. $=100 \mathrm{mg} / \mathrm{L}$, biomass conc. $=3 \mathrm{~mL}$ )

Effect of quinoline concentration: To study the effect of the initial quinoline concentration which is used as the sole source of carbon and nitrogen in all experiments on degradation, the degradation was carried out at three different initial concentrations of $100 \mathrm{mg} / \mathrm{L}, 250 \mathrm{mg} / \mathrm{L}$, and $500 \mathrm{mg} / \mathrm{L}$ using the pre-cultured biomass. The biodegradation of quinoline at three different initial concentrations is shown in Fig. 5.

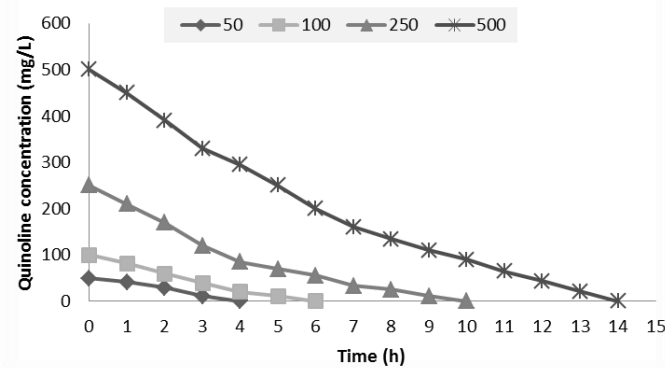

Fig.5: Biodegradation of quinoline at different initial concentrations (Biomass conc. $=3 \mathrm{~mL}$, bead size $=4 \mathrm{~mm}$ )

It can be seen from Fig. 5 that when the initial concentration of quinoline was relatively low, the non-acclimated activated sludge which entrapped in PVA-Ca alginate beads could degrade the quinoline very quickly without the lag-phase duration. For example, at the initial concentration of $100 \mathrm{mg} / \mathrm{L}$ and $250 \mathrm{mg} / \mathrm{L}$, the microbial cells could degrade quinoline within 6 and 10h, respectively. While the concentration of $500 \mathrm{mg}$ quinoline / $\mathrm{L}$ could be degraded within $14 \mathrm{~h}$. This could be attributed to the effect the degradation time by the increasing the inhibitory effect of the quinoline as its concentration was increased and indicated that the quinoline degradation rate was increased with the initial quinoline concentrations (within $500 \mathrm{mg} / \mathrm{L}$ ), the results were similar to the conclusion of (Wang et al., 2001; Xu et al., 2015).

Biodegradation in ALBR: The hydrogel beads were spiked with quinoline $(100 \mathrm{mg} / \mathrm{L})$ for a period of 5 days with continuous aeration in the ALBR. During the biodegradation process, nutrient medium $(500 \mathrm{~mL})$ was then added to the ALBR and saturated with oxygen by bubbling quinoline solution of $100 \mathrm{mg} / \mathrm{L}$. After saturating with oxygen, hydrogel beads were put in the ALBR. The repeated use of hydrogel beads for the degradation process was performed and the results indicated that the entrapped cells in the beads were active and stable for 4 successive repeated cycles with complete removal of quinoline. To detect degradation of quinoline, samples from the cultures, diluted in distilled water, were detected at $275 \mathrm{~nm}$ wavelengths by using a Perkin - Elmer spectrophotometer.

\section{Conclusions}

The use of activated sludge entrapped in hydrogel beads is a promising and attractive technology which does not only help to reveal in the quinoline degradation but also benefits the mechanism of the bio-treatment of wastewater contained quinoline and other refractory organic compounds. In the present study, optimizing the degradation conditions to achieve the complete quinoline degradation time of $100 \mathrm{mg} / \mathrm{L}$ was demonstrated as follows: polyvinyl-alcohol PVA concentration, $80 \% \mathrm{w} / \mathrm{v}$; calcium alginate concentration, $20 \% \mathrm{w} / \mathrm{v}$; initial biomass concentration the hydrogel bead, $3 \mathrm{~mL} / 10 \mathrm{~mL}$ of gel solution; and the hydrogel bead size, about $3 \mathrm{~mm}$ in diameter. The continuous-mode experiments were performed in ALBR and showed that the hydrogel beads could be repeatedly used for 4 successive cycles without breakage or loss of their stability, indicating that they have excellent mechanical strength, flexibility and swelling capacity. Thus, PVA-Ca alginate hydrogel beads have great potential to be cell-matrices in biotreatment of refractory organic compounds.

\section{References}

[1] Ahmad, M., Liu, S., Mahmood, N., Mahmood, A., Ali, M., Zheng, M., \& Ni, J. (2017). Synergic adsorption-biodegradation by an advanced carrier for enhanced removal of high-strength nitrogen and 
refractory organics. ACS applied materials \& interfaces, 9(15), 13188-13200.

[2] Aislabie, J., Bej, A. K., Hurst, H., Rothenburger, S., \& Atlas, R. M. (1990). Microbial degradation of quinoline and methylquinolines. Applied and environmental microbiology, 56(2), 345-351.

[3] Ali, M., \& Okabe, S. (2015). Anammox-based technologies for nitrogen removal: advances in process start-up and remaining issues. Chemosphere, 141, 144-153.

[4] An, M., \& Lo, K. V. (2001). Activated sludge immobilization using the PVA-alginate-borate method. Journal of Environmental Science and Health, Part A, 36(1), 101-115.

[5] Bai, Y., Sun, Q., Zhao, C., Wen, D., \& Tang, X. (2010). Bioaugmentation treatment for coking wastewater containing pyridine and quinoline in a sequencing batch reactor. Applied microbiology and biotechnology, 87(5), 1943-1951.

[6] Bajpai, S. K., \& Sharma, S. (2004). Investigation of swelling/degradation behaviour of alginate beads crosslinked with $\mathrm{Ca} 2+$ and $\mathrm{Ba} 2+$ ions. Reactive and Functional Polymers, 59(2), 129-140.

[7] Doria-Serrano, M. C., Ruiz-Trevino, F. A., Rios-Arciga, C., Hernandez-Esparza, M., \& Santiago, P. (2001). Physical characteristics of poly (vinyl alcohol) and calcium alginate hydrogels for the immobilization of activated sludge. Biomacromolecules, 2(2), 568574.

[8] Eisentraeger, A., Brinkmann, C., Hollert, H., Sagner, A., Tiehm, A., \& Neuwoehner, J. (2008). Heterocyclic compounds: toxic effects using algae, daphnids, and the Salmonella/microsome test taking methodical quantitative aspects into account. Environmental toxicology and chemistry, 27(7), 1590-1596.

[9] Felczak, A., Zawadzka, K., \& Lisowska, K. (2014). Efficient biodegradation of quinolone-Factors determining the process. International Biodeterioration \& Biodegradation, 96, 127-134.

[10] Fetzner, S., Tshisuaka, B., Lingens, F., Kappl, R., \& Hüttermann, J. (1998). Bacterial degradation of quinoline and derivativespathways and their biocatalysts. Angewandte Chemie International Edition, 37(5), 576-597.

[11] Gosmann, B., \& Rehm, H. J. (1986). Oxygen uptake of microorganisms entrapped in Ca-alginate. Applied microbiology and biotechnology, 23(3-4), 163-167.

[12] Jianlong, W., Liping, H., Hanchang, S., \& Yi, Q. (2001). Biodegradation of quinoline by gel immobilized Burkholderia sp. Chemosphere, 44(5), 1041-1046.

[13] Jianlong, W., Xiangchun, Q., Liping, H., Yi, Q., \& Hegemann, W. (2002). Microbial degradation of quinoline by immobilized cells of Burkholderia pickettii. Water Research, 36(9), 2288-2296.

[14] Kim, H. Y., Lee, O. M., Kim, T. H., \& Yu, S. (2015). Enhanced biodegradability of pharmaceuticals and personal care products by ionizing radiation. Water Environment Research, 87(4), 321-325.

[15] Lin, Q., \& Jianlong, W. (2010). Biodegradation characteristics of quinoline by Pseudomonas putida. Bioresource Technology, 101(19), 7683-7686.

[16] Lopes, T. J., \& Furlong, E. T. (2001). Occurrence and potential adverse effects of semivolatile organic compounds in streambed sediment, United States, 1992-1995. Environmental toxicology and chemistry, 20(4), 727-737.

[17] Sun, Q., Bai, Y., Zhao, C., Xiao, Y., Wen, D., \& Tang, X. (2009). Aerobic biodegradation characteristics and metabolic products of quinoline by a Pseudomonas strain. Bioresource technology, 100(21), 5030-5036.

[18] Wang, J. L., Wu, W. Z., \& Zhao, X. U. A. N. (2004). Microbial degradation of quinoline: kinetics study with Burkholderia picekttii. Biomedical and Environmental Sciences, 17(1), 21-26.

[19] Wang, L., Li, Y., \& Duan, J. (2014). Biodegradation of 2methylquinoline by Klebsiella pneumoniae TJ-A isolated from acclimated activated sludge. Journal of Environmental Science and Health, Part A, 49(1), 27-38.

[20] Xu, P., Ma, W., Han, H., Hou, B., \& Jia, S. (2015). Biodegradation and interaction of quinoline and glucose in dual substrates system. Bulletin of environmental contamination and toxicology, 94(3), 365-369.

[21] Zhang, L. S., Wu, W. Z., \& Wang, J. L. (2007). Immobilization of activated sludge using improved polyvinyl alcohol (PVA) gel. Journal of environmental sciences, 19(11), 1293-1297 